\title{
RESEARCH
}

Open Access

\section{Simple and efficient method for the quantification of antiepileptic drugs in human plasma by using magnetic graphene oxide- $\beta$-cyclodextrin composite as a sorbent}

Babji Palakeeti, K. Vijendar Reddy, K. Vengatajalabathy Gobi, Pothuraju Nageswara Rao and Jugun Prakash Chinta* (D)

\begin{abstract}
Background: In recent days, solid-phase extraction methods are widely utilized for the extraction of drug molecules from plasma samples due to their easy operating procedures and low matrix effect. The trace-level solidphase extraction of three structurally related antiepileptic drugs brivaracetam (BVC), eslicarbazepine acetate (ESL), and carbamazepine (CBZ) was investigated by using a magnetic porous material graphene oxide- $\beta$-cyclodextrin (MGO-CD). Morphology, magnetic properties, and structure of the synthesized MGO-CD were characterized by using FT-IR, SEM, XRD, and VSM.

Results: Solid-phase extraction (SPE) methods were used to extract the analytes from human plasma. Different extraction solvents such as acetonitrile (ACN), methanol $(\mathrm{MeOH})$, acetone, chloroform $\left(\mathrm{CHCl}_{3}\right)$, tertiary butyl diethyl ether (TBDE), and ethyl acetate (EtOAc) with variable polarities were used to extract drug molecules from MGO-CD. The linearity analysis showed good correlation coefficient values $\left(R^{2}\right)$ of $0.9989,0.9995$, and 0.9982 for BVC, ESL, and CBZ respectively. The LOD and LOQ ranges were found to be $6.14-28.32 \mathrm{ng} \mathrm{mL}^{-1}$ and $20.45-94.31 \mathrm{ng} \mathrm{mL}^{-1}$ respectively.

(Continued on next page)
\end{abstract}

\footnotetext{
* Correspondence: jugun@nitw.ac.in

Department of Chemistry, National Institute of Technology Warangal,

Warangal, Telangana 506004, India
}

\section{SpringerOpen}

(c) The Author(s). 2021 Open Access This article is licensed under a Creative Commons Attribution 4.0 International License, which permits use, sharing, adaptation, distribution and reproduction in any medium or format, as long as you give appropriate credit to the original author(s) and the source, provide a link to the Creative Commons licence, and indicate if changes were made. The images or other third party material in this article are included in the article's Creative Commons licence, unless indicated otherwise in a credit line to the material. If material is not included in the article's Creative Commons licence and your intended use is not permitted by statutory regulation or exceeds the permitted use, you will need to obtain permission directly from the copyright holder. To view a copy of this licence, visit http://creativecommons.org/licenses/by/4.0/. 
(Continued from previous page)

Conclusion: The high accuracy and precision made the developed HPLC method with MGO-CD a suitable alternative for the bioequivalence study of BVC, ESL, and CBZ in human plasma. This developed HPLC-UV method has good efficiency for recoveries and good linearity and is simple to handle. And also, it gave low retention time for the three antiepileptic drugs within $8 \mathrm{~min}$. It provides high efficiency for the extraction of trace-level substances from human plasma.

Keywords: Solid-phase extraction, HPLC, Magnetic graphene oxide, Cyclodextrin, Antiepileptic drugs

\section{Background}

Epilepsy is a chronic brain disease described by sudden and transient brain dysfunction caused by recurrent episodes of neurons in the brain [1-3]. It is identified with symptoms like seizures and should be treated immediately with a quick-acting antiepileptic drug (AED). The treatment results in lowering the potential sequelae, predominantly excitotoxic and ischemic neuronal cell loss, which initiates within minutes of uninterrupted seizure activity [4-8]. Brivaracetam (BVC), eslicarbazepine acetate (ESL), and carbamazepine (CBZ) drugs are widely used drugs for the treatment of this condition (Fig. 1) [9]. The IUPAC name of BVC is ((2S)-2-[(4R)-2oxo-4-propylpyrrolidin-1-yl]), which is a 4-n-propyl equivalent of racetum and levetiracetam derivative and is primarily employed for partial onset of seizures in adults and adolescents $[10,11]$. The mode of action of $\mathrm{BVC}$ is through binding to the pervasive synaptic vesicle glycoprotein 2A (SV2A), like levetiracetam but has a 20fold greater affinity [12-15]. CBZ is a mood-stabilizing and anticonvulsant tricyclic lipophilic drug. This drug is the first one to treat epilepsy for psychomotor and partial onset of seizures and is also used for variability of indications, including schizophrenia, attention-deficit hyperactivity disorder (ADHD), paroxysmal dangerous pain disorder, phantom limb disease, and post-traumatic stress syndrome [16-18].

ESL is a modern and third-generation single enantiomer drug that belongs to the dibenzoazepine family. ESL is an anticonvulsant medication, effectively administrated in the adjunctive therapy for partial-onset seizures $[19,20]$. ESL is a prodrug that is intensively transformed to eslicarbazepine, which is an important metabolite in the human body [21-23]. ESL was known to wield anticonvulsant activity by inhibiting the repetitive neuronal firing and also by stabilizing the inactive sodium channels [24-26].

Considering the importance of these molecules as antiepileptic drugs, it is important to develop an analytical method for the extraction of these drugs from biological fluids. The available literature revealed that the different analytical methods such as fluorescence-based immunoassays, enzyme-linked immunosorbent assays, electrochemical, and spectrophotometric methods are known for extraction of these drugs. These methods give results with high accuracy and sensitivity and also rapidly by using a small amount of blood sample. But the main drawback with these methods is their high operating costs. Solid-phase extraction (SPE) method is the commonly used extraction method compared with liquid-liquid extraction (LLE) due to its advantages such as high preconcentration value, low solvent consumption, and easy handling. Adsorbent plays a key role in the SPE method; various adsorbents such as simple graphene oxide, silica gel, activated carbon, ionic liquids, calixarenes, and chelating resins were reported. But these materials normally showed low

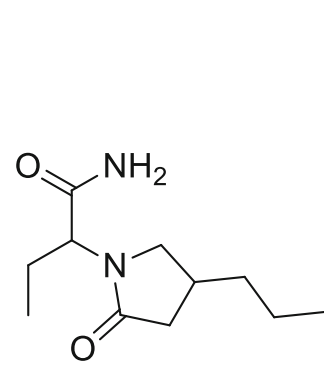

a<smiles>CC(=O)OC1Cc2ccccc2N(C(N)=O)c2ccccc21</smiles>

b
M.F : $\mathrm{C}_{17} \mathrm{H}_{16} \mathrm{~N}_{2} \mathrm{O}_{3}$ M.W : 296.32<smiles>NC(=O)N1c2ccccc2C=Cc2ccccc21</smiles>

c

M.F : $\mathrm{C}_{15} \mathrm{H}_{12} \mathrm{~N}_{2} \mathrm{O}$

M.W : 236.27

Fig. 1 Chemical structures of a brivaracetam, $\mathbf{b}$ eslicarbazepine acetate, and $\mathbf{c}$ carbamazepine 
absorbance values and made the elution procedure critical. Therefore, the development of a method which overcomes all the limitations mentioned here is of utmost importance for the analysis of drugs in biological samples.

In the current method, iron oxide-graphene oxide- $\beta$ cyclodextrin composite was used as an adsorbent. Bcyclodextrin is a cyclic oligosaccharide consisting of seven $\mathrm{D}$-glucopyranose units bound by $\beta$-1, 4-glycosidic bonds [27]. The usage of $\beta$-cyclodextrin in the composite further increases the adsorption capacity due to the presence of a hydrophilic outer shell due to the presence of more hydroxyl groups and hydrophobic cavity due to its corban chain conformation. Owing to this dual character, it acts as the host-guest moiety by capturing compounds with suitable dimensions into its cavity [28-31]. Enrichment capability and high supramolecular recognitions of $\beta$-cyclodextrin are widely used in different analytical aspects especially in separation methods [32, 33]. Graphene oxide (GO), the other component of the composite, is made through the oxidation of graphene. It contains hydroxyl, carboxyl, and epoxide derivative as functional groups, which increases the dispersibility in the solution. GO is known for its exceptional electrical, optical, and mechanical properties due to the high surface area. Thus, the combination of these three components makes this composite an ideal adsorbent for the extraction of drugs from plasma. Iron oxide induces magnetic property to the adsorbent, and this made the extraction process easy and quick with low matrix effect and high recovery percentage of analytes. There is no need to go for high-speed centrifugation; instead, a simple magnet can be used for the separation. The MGO-CD was prepared through the encapsulation of $\beta$-cyclodextrin on MGO with the help of linker tetrafluoterthalonitrile. The liker tetrafluoterthalonitrile helped to build a porous structure of MGO and $\beta$-cyclodextrin via nucleophilic aromatic substitution reactions [34]. The MGO-CD morphology, structure, and magnetic nature were confirmed by using SEM, VSM, IR, and XRD studies. Simultaneous identification and quantification synergy of BVC, ESL, and CBZ in human blood plasma by using MGO-CD as solid phase has been accomplished with HPLC.

\section{Methods}

\section{Materials}

All the chemicals and solvents used in the current studies are of analytical grade. Graphene powder, $\mathrm{FeCl}_{3} \cdot 6 \mathrm{H}_{2} \mathrm{O}$, and ammonium hydroxide solution (28.0-30\% $\mathrm{NH}_{3}$ basis) were procured from SigmaAldrich. Acetonitrile, methanol, chloroform, TBDE, acetone, ethanol, ethyl acetate, and DMF were purchased from (Merck) Mumbai, India. Double distilled deionized water is used for the entire analysis. Tetrafluoroterepthalonitrile, $\beta$-cyclodextrin (>98\%), sodium acetate, and mono-, di-, and polyethylene glycol were procured from Sigma-Aldrich. CBZ, BVC, and ESL were obtained as gifted samples from Mylan \& Hetero laboratories.

\section{Instruments and analytical conditions}

HPLC having a binary pump system with a diode array detector and LC-Solutions software (Shimadzu, Japan) was used for developing the method. Luna RP C18 $(4.6 \times 150 \mathrm{~mm}, 5 \mu)$ column was used, and column oven temperature was maintained at ambient conditions. Acetonitrile and $0.1 \%$ formic acid (65:35) mixture was used as a mobile phase. FT-IR spectra were recorded on Perkin Elmer, USA, using $\mathrm{KBr}$ pellets at ambient temperature. Powder X-ray diffractograms of GO, MGO, and synthesized MGO-CD were recorded by using a Bruker AXS D8 diffractometer with $\mathrm{Cu} \mathrm{K}_{\alpha}$ radiation $\left(1.5406 \mathrm{~A}^{\circ}\right)$, step size $2 \mathrm{mdeg}$, and $0.5 \mathrm{~s}$ per step scan speed. The morphology of MGO-CD was analyzed by FEI Apreo LoVac equipped with an Aztec Standard EDX System. The magnetic properties of samples were measured at room temperature by using a vibrational sample magnetometer (VSM, Lakeshore 7400, Westerville, OH, USA) in magnetic fields up to $15 \mathrm{kOe}$. Raman spectra were taken on a SENTERRA Dispersive Raman microscope (Bruker, Germany) with a wavelength $785.0 \mathrm{~nm}$ incident laser light.

\section{Synthetic procedure for MGO-CD Synthesis of graphene oxide}

Modified Hummer's method was used for the synthesis of graphene oxide (GO) from graphite nanopowder with a set of modifications (Fig. 2) [35]. In brief, graphite powder $(2 \mathrm{~g})$ was added slowly into 50 $\mathrm{mL}$ of concentrated sulfuric acid, and for this black mixture, $2 \mathrm{~g}$ of sodium nitrate was added for initiating the reaction. For the above reaction mixture, potassium permanganate was added by maintaining the temperature below $20{ }^{\circ} \mathrm{C}$. The resultant mixture was stirred at $60^{\circ} \mathrm{C}$ for $4 \mathrm{~h}$. At this stage, the temperature was raised up to $90{ }^{\circ} \mathrm{C}$ after adding the $100 \mathrm{~mL}$ of deionized water and stirred for $15.0-20.0 \mathrm{~min}$. The addition of $20 \mathrm{~mL}$ of $30 \% \mathrm{H}_{2} \mathrm{O}_{2}$ and $200 \mathrm{~mL}$ of warm water resulted in a color change to bright yellow which indicates the formation of GO. The solid was collected and washed several times with 5\% hydrochloric acid and water and then dried for $12 \mathrm{~h}$.

\section{Synthesis of MGO}

MGO was prepared with the help of a simple and ecofriendly solvothermal route [36]. The GO $(0.2 \mathrm{~g})$ was dispersed into a $250-\mathrm{mL}$ round bottom flask containing 


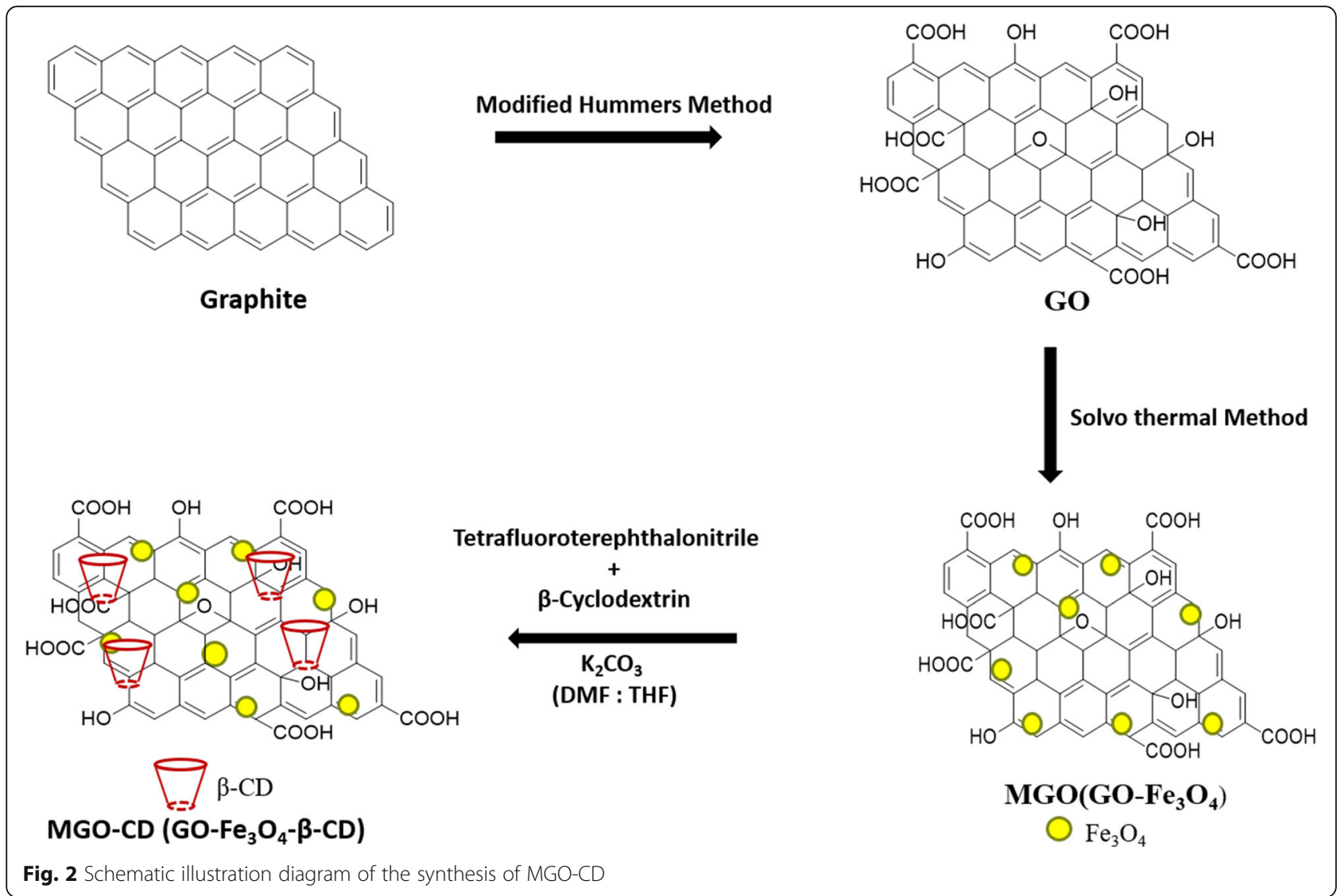

the mixture of mono- $(20 \mathrm{~mL})$ and di-ethylene glycol $(60 \mathrm{~mL})$ and sonicated for about $2 \mathrm{~h}$. To this, $0.68 \mathrm{~g}$ of $\mathrm{FeCl}_{3} \cdot 6 \mathrm{H}_{2} \mathrm{O}$ was added and the dispersion was stirred for $25 \mathrm{~min}$. Thereafter, polyethylene glycol $(2.25 \mathrm{~g})$ and sodium acetate $(8.10 \mathrm{~g})$ were added slowly and sonicated for $30 \mathrm{~min}$. The reaction mixture was transferred into a stainless-steel autoclave and the reaction is carried out at $180^{\circ} \mathrm{C}$ for $12 \mathrm{~h}$. Finally, the formed product was collected by using centrifugation and washed several times with water and ethanol and then dried for $12 \mathrm{~h}$ at $50^{\circ} \mathrm{C}$ in a vacuum oven.

\section{Preparation of MGO-CD composite}

MGO $(0.0615 \mathrm{~g})$, tetrafluoroterphthalonitrile $(0.4 \mathrm{~g})$, cyclodextrin $(0.615 \mathrm{~g})$, and potassium carbonate $(0.96$ g) were taken in a three-neck round bottom flask containing the solvent mixture of tetrahydrofuran (THF, $4 \mathrm{~mL}$ ) and dimethylformamide (DMF, $26 \mathrm{~mL}$ ). The reaction mixture was deoxygenated by purging nitrogen gas for about $30 \mathrm{~min}$. After that, the reaction mixture was stirred mechanically at $85^{\circ} \mathrm{C}$ with constant speed for about $24 \mathrm{~h}$. After the completion of reaction time, the formed product was collected by using centrifugation for $5.0 \mathrm{~min}$ at $5000 \mathrm{RPM}$. Then, the product was washed with deionized water and $\mathrm{HCl}$ until the supernatant is neutralized. Further, the product was washed with THF and dichloromethane for the removal of unbounded cyclodextrin and dried at $50{ }^{\circ} \mathrm{C}$ in the oven for $10 \mathrm{~h} \mathrm{[34].}$

\section{Preparation of standard and spiked human plasma sample solutions}

The standard stock solutions of BVC, ESL, and CBZ $\left(1000 \mu \mathrm{g} \mathrm{mL}^{-1}\right)$ were prepared by dissolving in acetonitrile and stored at $4{ }^{\circ} \mathrm{C}$ in the refrigerator. The drug-free human plasma was collected from our institute dispensary and stored at $-20{ }^{\circ} \mathrm{C}$. The protein content from the plasma was removed by adding 1 $\mathrm{mL}$ acetonitrile $1: 4(\mathrm{v} / \mathrm{v})$ ratio to $250 \mu \mathrm{L}$ of plasma 2$\mathrm{mL}$ Eppendorf tube. The sample was vortexed for 5 min and then centrifuged for $4 \mathrm{~min}$ at $4000 \mathrm{rpm}$. We repeated this procedure to getting $4 \mathrm{~mL}$ of supernatant. The $4 \mathrm{~mL}$ of supernatant was taken in a 5$\mathrm{mL}$ glass vial and dried with $\mathrm{N}_{2}$ gas at $40^{\circ} \mathrm{C}$ in a vacuum oven. For the reconstitution of the solution, phosphate buffer ( $\mathrm{pH}$ 7.2) solution was added to the residue. In order to construct the calibration curve, eight spiked plasma sample solutions containing the abstained final concentrations of three antiepileptic drugs of BVC, ESL, and CBZ (0.5-50.0, 0.1-40.0, and $0.25-60.0 \mu \mathrm{g} \mathrm{mL}^{-1}$ respectively) were prepared. For QC analysis, three-level spiked sample solutions (low: 

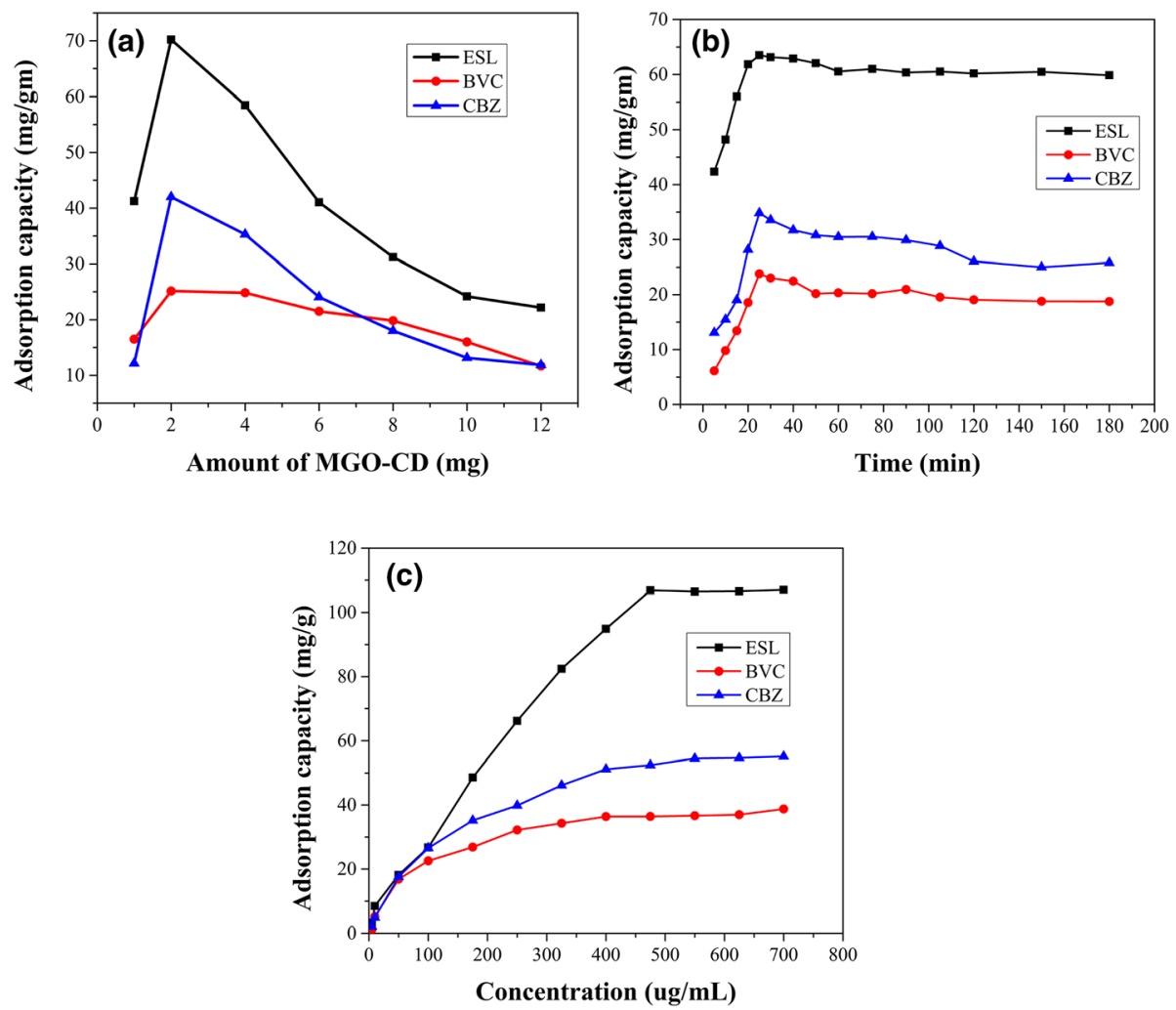

Fig. 3 a Adsorption capacity of MGO-CD. b The study of adsorption kinetics. $\mathbf{c}$ The study of adsorption isotherm

BVC, ESL, and CBZ is $1.0,0.5$, and $0.75 \mu \mathrm{g} \mathrm{mL}^{-1}$; middle: $10.0,5.0$, and $7.5 \mu \mathrm{g} \mathrm{mL}^{-1}$; high: 20.0, 10.0 , and $15.0 \mu \mathrm{g} \mathrm{mL}^{-1}$ ) were prepared. Eighteen milligrams of MGO-CD was added and then the solutions were mixed up to $25.0 \mathrm{~min}$. The MGO-CD was separated from the solution by using a strong magnet. The analytes are extracted with $1.0 \mathrm{~mL}$ acetonitrile through ultrasound, and the solution was evaporated and reconstituted with acetonitrile. From this, $20 \mu \mathrm{L}$ solution was directly injected into HPLC for analysis.

\section{The study of MGO-CD properties}

\section{Adsorption capacity of MGO-CD}

Different amounts of MGO-CD (1.0-12.0 mg) in different centrifuge tubes were taken and then three antiepileptic drugs at a concentration of each $100.0 \mu \mathrm{g} / \mathrm{mL}$ were added. After continuous shaking of this mixture up to $120.0 \mathrm{~min}$, the supernatant was collected by a strong external magnet and then directly injected into HPLC (Fig. 3a).

\section{The study of adsorption kinetics}

Ten milliliters of three antiepileptic drug solution containing concentrations of each BVC, ESL, and CBZ $(100.0 \mu \mathrm{g} / \mathrm{mL})$ was taken and added $18.0 \mathrm{mg}$ of MGO-
CD for the study of adsorption kinetics. The mixture was shaken continuously with different time ranges from 5 to $180.0 \mathrm{~min}$. The unbounded solution was separated by using a strong external magnet and directly injected into HPLC analysis (Fig. 3b).

\section{Study of adsorption isotherm}

For the study of adsorption isotherm, $2 \mathrm{mg}$ of MGO$\mathrm{CD}$ in $1-\mathrm{mL}$ drug solutions with different concentrations $\left(5.0-700.0 \mu \mathrm{g} \mathrm{mL}^{-1}\right)$ was taken. The solutions are kept for $30.0 \mathrm{~min}$ and then supernates were collected from MGO-CD by using a strong magnet. $20.0 \mu \mathrm{L}$ of each supernate was directly injected into HPLC-UV and the concentrations are determined (Fig. 3c).

\section{Results}

\section{Characterization of synthesized MGO-CD}

The magnetic graphene oxide and cyclodextrin (MGO-CD) composite was synthesized as depicted in the experimental details. The MGO-CD composite was characterized by FT-IR, powder XRD, SEM, and VSM. The MGO showed one specific band at 591 $\mathrm{cm}^{-1}$ in the infra-red spectrum which corresponds to the $\mathrm{Fe}-\mathrm{O}$ vibration in $\mathrm{Fe}_{3} \mathrm{O}_{4}$. The MGO-CD exhibited 


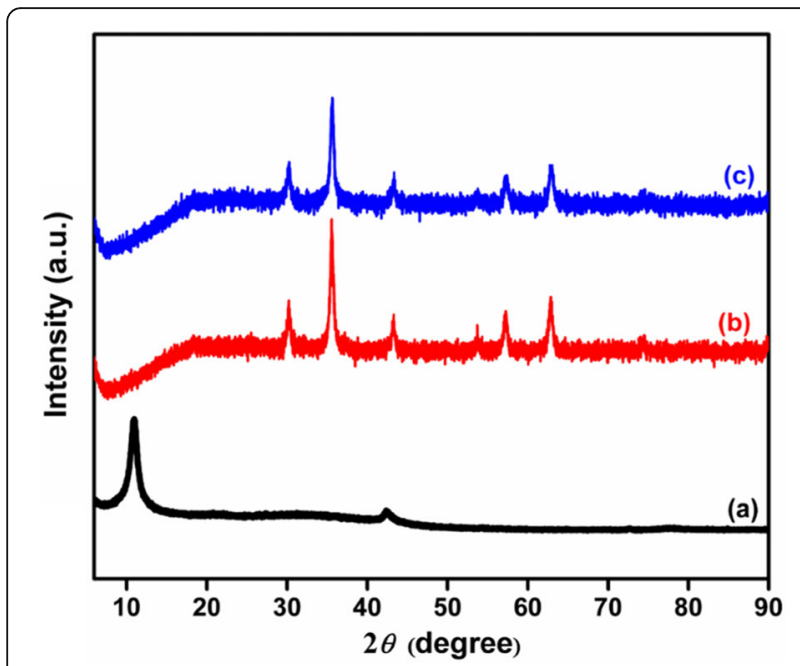

Fig. 4 XRD patterns of (a) GO, (b) MGO, and (c) MGO-CD

an additional band at $2255 \mathrm{~cm}^{-1}$ attributed to the stretching frequency of $-\mathrm{C} \equiv \mathrm{N}$ in the linker (Fig. S1). The IR spectra also exhibited a weak band at 1156 $\mathrm{cm}^{-1}$, and strong peaks at 1422 and $1580 \mathrm{~cm}^{-1}$ correspond to $\mathrm{C}-\mathrm{F}$ and aromatic $\mathrm{C}=\mathrm{C}$ stretching frequencies respectively. The stretching frequencies of $\mathrm{O}-\mathrm{H}$, $\mathrm{C}-\mathrm{H}$, and $\mathrm{C}-\mathrm{O}$ were also found at 3453,2945 , and $1032 \mathrm{~cm}^{-1}$. These results suggested the formation of magnetic graphene oxide cyclodextrin composite (MGO-CD).

Powder X-ray diffractogram of GO exhibited a peak at $10.56^{\circ}$ which corresponds to the characteristic diffraction from graphitic carbon in exfoliated GO. The peak was disappeared in both MGO and MGO-CD due to the disturbance in stacking of $\mathrm{GO}$ sheets after

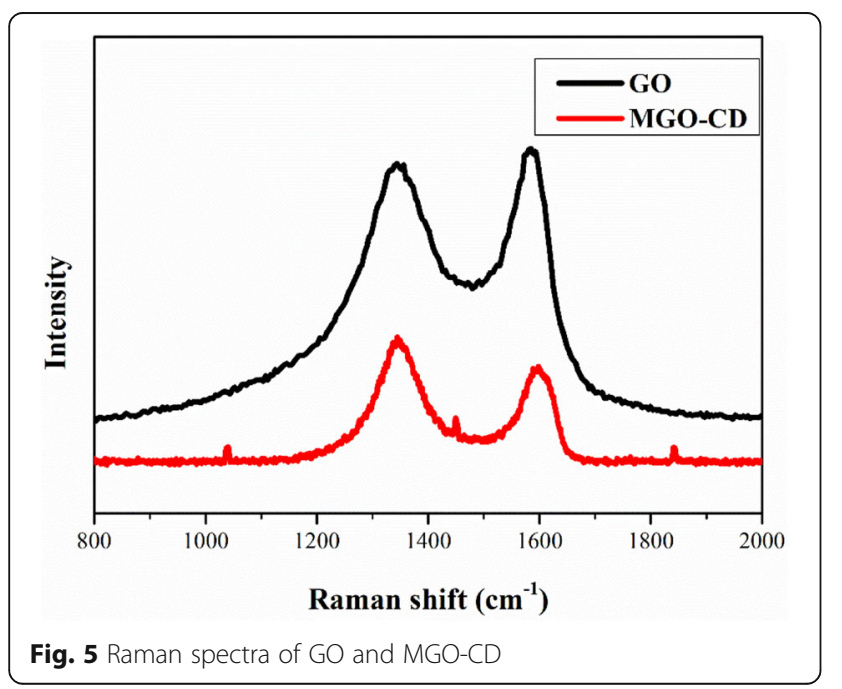

loading with iron oxide $\left(\mathrm{Fe}_{3} \mathrm{O}_{4}\right)$ and $\mathrm{CD}$. The diffraction peaks observed at $30.0^{\circ}, 35.9^{\circ}, 43.0^{\circ}, 53.2^{\circ}, 57.3^{\circ}$, and $62.4^{\circ}$ were assigned to (220), (311), (400), (422), (511), and (440) planes, which corresponds to the cubic phase of $\mathrm{Fe}_{3} \mathrm{O}_{4}$ with a face-centered cubic structure as found in the literature reports. The intensity of XRD peaks was found to be slightly decreased on loading with cyclodextrin. These results supported the incorporation of CD onto MGO (Fig. 4).

There will be irregularity that occurred in the sp2 carbon network in GO, due to the incorporation of $\mathrm{CD}$ and Fe3O4. Hence, the ordered and disordered crystal structures of fabricated MGO-CD need to be investigated using Raman spectroscopy. The obtained Raman spectra of GO and MGO-CD are plotted in Fig. 5. D-band and G-band are the parameters corresponding to the structural defects and imperfections, and first-order scattering of the E2g phonon of the sp2 carbon domains, respectively. From the spectrum of GO, it can be observed that D-band and G-band are assigned at 1345 and $1585 \mathrm{~cm}^{-1}$, respectively. The disordering in the structure of $\mathrm{GO}$ is measured using the intensity ratio of ID/IG. It can also be observed that there is an increase in the intensity ratio of MGO-CD than that of GO due to the incorporation of $\mathrm{CD}$ and $\mathrm{Fe} 3 \mathrm{O} 4$, which indicates a significant amount of structural defects of the $\mathrm{sp} 2$ carbon network in GO.

The morphology of the synthesized composite was examined by SEM. Figure 6a shows a sheet-like structure of the exfoliated GO. This was further employed for the synthesis of MGO-CD composites. There was clear diffraction observed from Fig. $6 \mathrm{~b}$ that shows the formation of $\mathrm{Fe}_{3} \mathrm{O}_{4}$ composites on the $\mathrm{GO}$ sheets. The particles have been observed clearly along with the stacking of the GO sheets because of the adherence of $\mathrm{Fe}_{3} \mathrm{O}_{4}$ and $\mathrm{CD}$.

The vibrational sample magnetometer (VSM) data was collected to understand the magnetic properties of MGO-CD; the hysteresis loops of MGO-CD are shown in Fig. 7. S-like curves of magnetic hysteresis loops observed indicate the paramagnetic nature of MGO-CD because of no remnant magnetization or coercivity at room temperature. The specific saturation magnetization (Ms) of the composite was observed to be $43.96 \mathrm{emu} \mathrm{g}^{-1}$, which is appropriate for the separation of composites with a magnet. The MGO-CD could be easily separated from the mixture of composites in the solution by placing a permanent magnet.

\section{Optimization of extraction conditions}

In this method, parameters such as extraction solvent (eluent) (ACN, $\mathrm{MeOH}$, acetone, $\mathrm{CHCl}_{3}, \mathrm{TBDE}$, and 

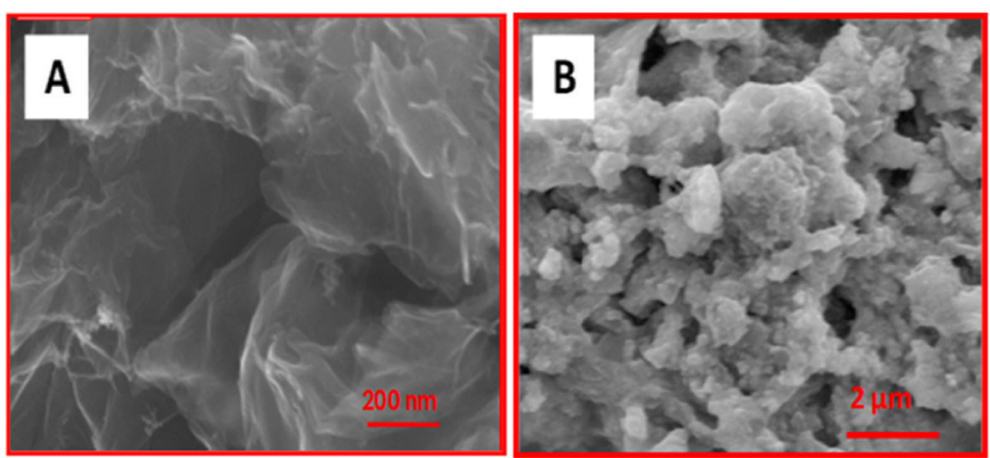

Fig. 6 SEM images of $\mathbf{a} G O$ and $\mathbf{b} M G O-\beta-C D$

EtOAc), sorbent amount (2.0-22.0 mg), extraction time (intermissions from 5.0-30.0 $\mathrm{min}$ ), and eluent amount ( 0.5 to $2.5 \mathrm{~mL}$ ) were optimized. The mixture of three antiepileptic drug solution contains the concentrations of BVC $\left(10.0 \mu \mathrm{g} \mathrm{mL}^{-1}\right), \quad$ ESL $\left(10.0 \mu \mathrm{g} \mathrm{mL}^{-1}\right)$, and CBZ $\left(20.0 \mu \mathrm{g} \mathrm{mL}^{-1}\right)$ respectively.

\section{Rate of adsorption}

In order to get the amount of adsorbent required for better extraction, the effect of adsorbent quantity on the extraction of these drugs was studied. These studies revealed that at $2.0 \mathrm{mg}$ of absorbent, the adsorption rates were found to be $33.50 \%$ (ESL), $17.95 \%$ (CBZ), and $8.19 \%$ (BVC). Increasing in the four-unit volume of the adsorbent amount, the adsorption rate for ESL gradually increased and it reaches equilibrium $(97.62 \%)$ at $18.0 \mathrm{mg}$. In the case of $\mathrm{BVC}$, the rate of adsorption was slow up to $10.0 \mathrm{mg}$ and it reaches maximum $(83.08 \%)$ at $18 \mathrm{mg}$ whereas the adsorption rate for CBZ was gradually increased (87.98\%) and

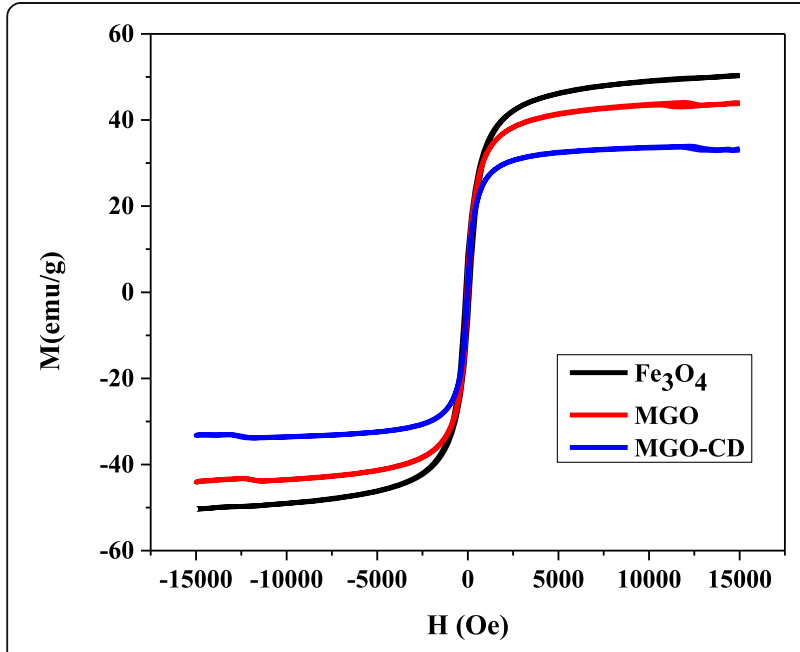

Fig. 7 Magnetization hysteresis loops of $\mathrm{Fe}_{3} \mathrm{O}_{4}, \mathrm{MGO}$, and $\mathrm{MGO}-\mathrm{CD}$ reaches maximum at $18.0 \mathrm{mg}$ (Fig. 8a). These studies suggest that the maximum rate of adsorption was found to be at $18.0 \mathrm{mg}$ in all the three drugs.

\section{Effect of eluent solvent}

The choice of desorption solvent plays a significant role in the extraction of analytes from the adsorbent. In the previous methods of extraction of these three drugs, acetonitrile, methanol, acetone, and a mixture of solvents under acidic conditions were used. In the present method, methanol, TBDE, acetone, acetonitrile, chloroform, and ethyl acetates were used as desorption solvents. Based on the polarity scale, acetonitrile is expected to give high desorption efficiency for these three antiepileptic drugs among all solvent used and chloroform is of low eluting efficiency. The same pattern has been found in our experimental results (Fig. 8b). The percentage recovery of these three drugs was found to be higher in the case of acetonitrile and lower with chloroform as eluent. From the HPLC chromatograms, the polarity sequence of the three antiepileptic drugs is BVC > ESL > CBZ respectively (Fig. 9).

\section{Effect of eluent amount}

The rate of desorption of analytes from any adsorbent is known to depend not only on the nature of the eluent but also on the amount. To study the effect of eluent amount on desorption rate, different volumes of eluent were used from 0.5 to $2.5 \mathrm{~mL}$. The studies clearly suggested that the $1.5 \mathrm{~mL}$ of eluent gives maximum desorption of drugs (Fig. 8c). The variation was found to be in the range of $10 \%$ between 0.5 and $2.5 \mathrm{~mL}$. Based on these studies, $1.5-\mathrm{mL}$ eluent volume was found to be the optimal condition to get the best desorption efficiency.

\section{Effect of time on the extraction}

Time also showed a significant effect on the desorption of three antiepileptic drugs from MGO-CD. The effect of time on extraction has been studied between 5.0 and 

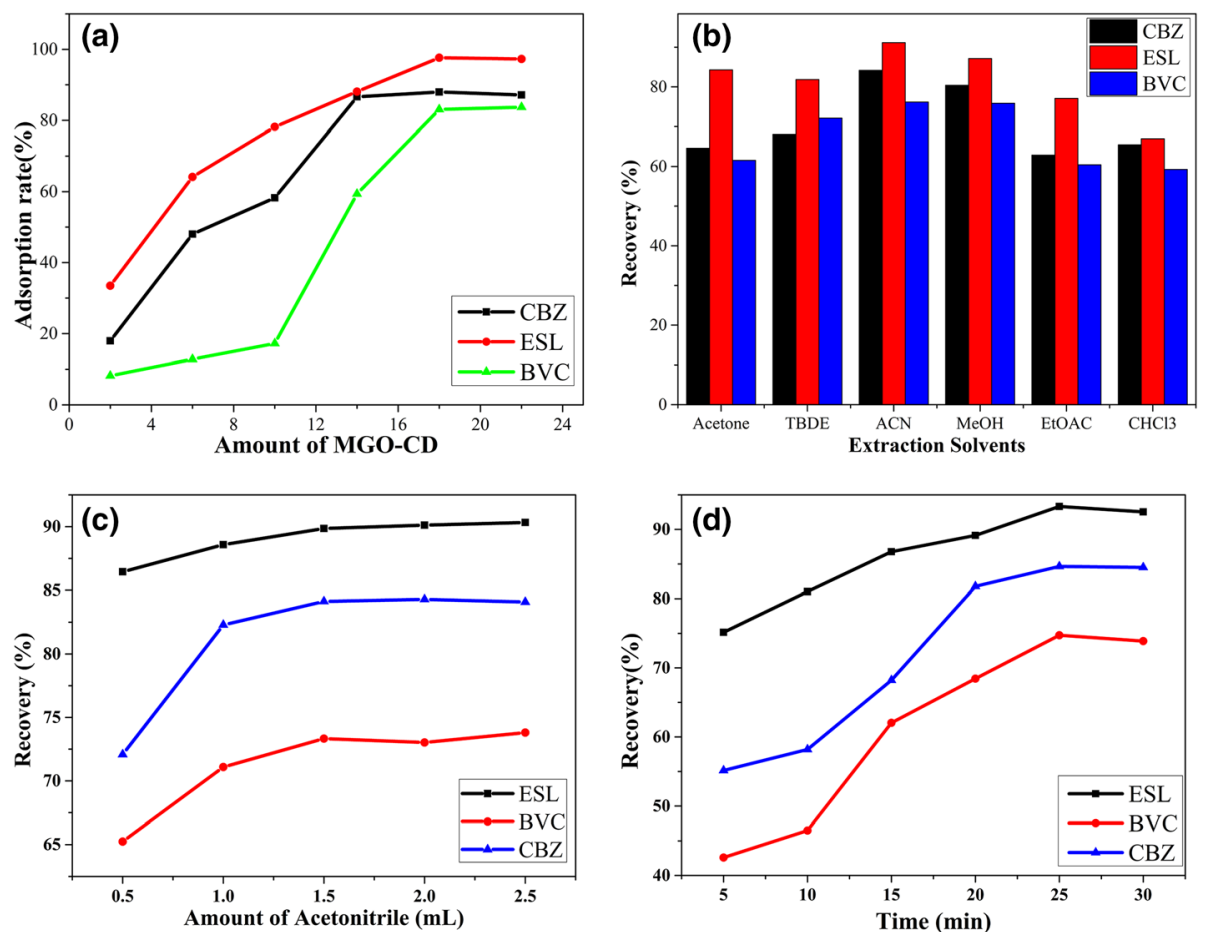

Fig. 8 a The effect of MGO-CD amount. $\mathbf{b}$ The effect of deferent solvents. $\mathbf{c}$ The effect of solvent amount. $\mathbf{d}$ The effect of time on extraction

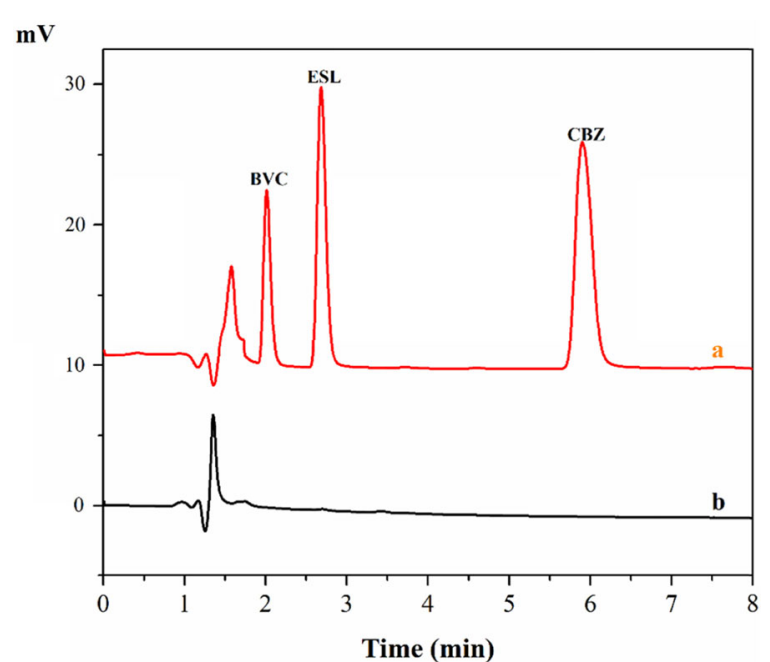

Fig. 9 Typical HPLC chromatograms of the (a) human blank plasma sample after the extraction and (b) spiked sample solution after extraction with SPE at a low-level concentration
30.0 min. From Fig. 8d, it is clear that the extraction increases with the increase in time from 5.0 to $20.0 \mathrm{~min}$ (up to $30 \%$ ) and becomes saturated after $25.0 \mathrm{~min}$. Based on this study, the optimized desorption was found to be 20.0 min for effective desorption of these drugs from the MGO-CD.

\section{Adsorption capacity}

For the evolution and determination of adsorption capacity of MGO-CD, different initial concentrations of drug solutions $\left(5.0-700.0 \mu \mathrm{g} \mathrm{mL}^{-1}\right)$ were prepared. The equilibrium adsorption capacity $Q_{\mathrm{e}}(\mathrm{mg} / \mathrm{g})$ of MGO-CD was measured by changing the concentrations of sample solutions and the values were calculated by using the subsequent equation.

$$
\mathrm{Q}_{\mathrm{e}}=\left(\mathrm{C}_{0}-\mathrm{C}_{\mathrm{e}}\right) \mathrm{V} / \mathrm{m}
$$

where $Q_{\mathrm{e}}(\mathrm{mg} / \mathrm{g})$ is the amount of three antiepileptic drugs adsorbed per unit weight of adsorbent at equilibrium, $C_{0}\left(\mu \mathrm{g} \mathrm{mL}^{-1}\right)$ is the initial concentration, $C_{\mathrm{e}}(\mu \mathrm{g}$ $\mathrm{mL}^{-1}$ ) is the equilibrium concentrations of drugs in the solution, $m(\mathrm{~g})$ is the mass of MGO-CD, and $V(\mathrm{~L})$ is the volume of the sample solution.

The apparent binding amount of the MGO-CD was calculated by using the following Langmuir isotherm model. 
Table 1 Analytical parameters of the three antiepileptic drugs' quantitative analysis

\begin{tabular}{|c|c|c|c|c|c|}
\hline Drug & Linear range $\left(\mu \mathrm{g} \mathrm{mL}^{-1}\right)$ & Calibration curve equation & $R^{2}$ & $\operatorname{LOD}\left(\mathrm{ng} \mathrm{mL}^{-1}\right)$ & LOQ $\left(\mathrm{ng} \mathrm{mL}^{-1}\right)$ \\
\hline Brivaracetam & $0.5-50$ & $y=36563 x+22801$ & 0.9989 & 28.32 & 94.31 \\
\hline Eslicarbazepine acetate & $0.1-40$ & $y=77215 x+15516$ & 0.9995 & 6.14 & 20.45 \\
\hline Carbamazepine & $0.25-60$ & $y=310443-47234$ & 0.9982 & 14.86 & 49.48 \\
\hline
\end{tabular}

$$
\mathrm{C}_{\mathrm{e}} / \mathrm{Q}_{\mathrm{e}}=\mathrm{C}_{\mathrm{e}}\left(1 / \mathrm{Q}_{\mathrm{m}}\right)+\left(1 / \mathrm{Q}_{\mathrm{m}} \mathrm{K}\right)
$$

where $K$ is the constant coefficient, $Q_{\mathrm{m}}$ is the maximum sorption capacity of the MGO-CD, $Q_{e}$ is the equilibrium sorption capacity, and $C_{\mathrm{e}}$ is the equilibrium concentration. This transformation $\left(C_{\mathrm{e}} / Q_{\mathrm{e}}\right.$ versus $\left.C_{\mathrm{e}}\right)$ gives information about the binding characteristics of the equilibrium adsorption. The $Q_{\mathrm{m}}$ values can be obtained from the plot of $C_{\mathrm{e}} / Q_{\mathrm{e}}$ versus $C_{\mathrm{e}}$. By using this transformation, the maximum sorption values for BVC, ESL, and CBZ were found to be 36.38, 106.86, and 54.49 $\mathrm{mg} \mathrm{g}^{-1}$ respectively.

\section{Method validation Linearity}

For the determination of linearity, six different concentrated solutions of three antiepileptic drugs were prepared in the range of $0.5-50.0,0.1-40.0$, and $0.25-60.0 \mu \mathrm{g} \mathrm{mL}^{-1}$ respectively for BVC, ESL, and CBZ. The calibration curves give good correlation coefficient $\left(R^{2}\right)$ values $\geq 0.9982$ with acceptable linearity (see Table 1).

\section{$\angle O D$ and $\angle O Q$}

The sensitivity of the method was assessed by measuring the limit of determination (LOD) and limit of quantification (LOQ). LOD and LOQ of the developed method were evaluated by using the signal to noise ratio $(\mathrm{S} / \mathrm{N})$ method. The LOD was set as the lowest concentration that can be distinguished with signal to noise ratio over 3 , whereas the lower limit of quantification of the analytes was assessed by using a signal to noise ratio of 10. The LOD for BVC, ESL, and CBZ were 28.32, 6.14, and $14.86 \mathrm{ng}$ $\mathrm{mL}^{-1}$ and LOQ values for BVC, ESL, and CBZ were 94.31, 20.45, and $49.48 \mathrm{ng} \mathrm{mL}^{-1}$ respectively.

\section{Precision and accuracy}

Precision and accuracy of the method were analyzed by preparing three different QC level samples as described in Table 2 (low, middle, and high) of three antiepileptic drugs BVC, ESL, and CBZ. Each level of QC samples was repeatedly injected in triplicate and evaluated the recovery percentage. Inter- and intraday recoveries of analytes results are shown in Table 2 . The results clearly showed the low interference effect on target analyte peaks and this demonstrates the good specificity of the method. From the results, it is clear that the recovery ranges in both intra- and interday are 80.25-101.11\% and CV ranges are $1.86-5.50 \%$. From these test results, it is clear that the developed HPLC method will be useful for the analysis of these three drugs in human plasma samples.

\section{Robustness}

The robustness of the current method was studied by preparing standard solutions of drugs $\left(10.0 \mu \mathrm{g} \mathrm{mL}^{-1}\right)$ and by varying conditions such as flow rate, column oven temperature, and mobile phase ratio. From Table 3, it is clear that no substantial difference in the results was observed at different chromatographic conditions and the RSD was found to vary between 5.84 and $1.42 \%$. These results indicate the reliability and the good performance of the developed HPLC method.

\section{Discussion}

The LC-MS method has been quite widely employed for the analysis of drugs in the plasma due to its high sensitivity and selectivity. But the method is expensive in terms of solvent usage and maintenance that increase the burden for institutions and patients which in turn limits the applicability of the method. In the case of liquid-liquid extractions, the method needs a high amount of organic solvents and it causes

Table 2 Intraday and interday precision and accuracy values of analytes in the plasma sample

\begin{tabular}{|c|c|c|c|c|c|c|}
\hline & \multicolumn{3}{|l|}{ Intraday (\%) } & \multicolumn{3}{|l|}{ Interday (\%) } \\
\hline & Low & Middle & High & Low & Middle & High \\
\hline Brivaracetam & $81.23 \pm 3.41$ & $84.65 \pm 4.24$ & $86.06 \pm 3.66$ & $80.25 \pm 3.72$ & $86.08 \pm 3.97$ & $87.61 \pm 4.11$ \\
\hline Eslicarbazepine acetate & $96.62 \pm 2.48$ & $98.68 \pm 1.84$ & $101.11 \pm 3.68$ & $95.02 \pm 4.63$ & $97.55 \pm 3.87$ & $99.13 \pm 3.22$ \\
\hline Carbamazepine & $91.27 \pm 4.43$ & $94.83 \pm 4.10$ & $98.36 \pm 3.45$ & $92.97 \pm 5.12$ & $95.63 \pm 3.88$ & $99.07 \pm 3.72$ \\
\hline
\end{tabular}




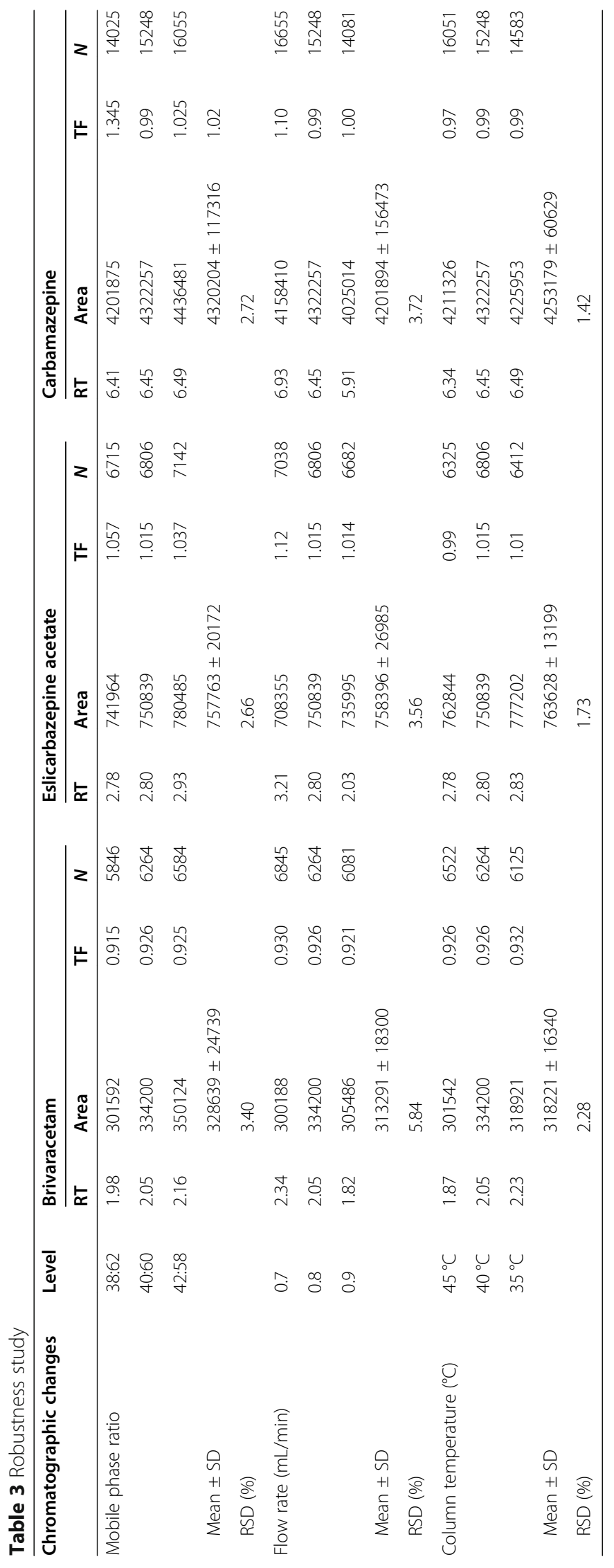




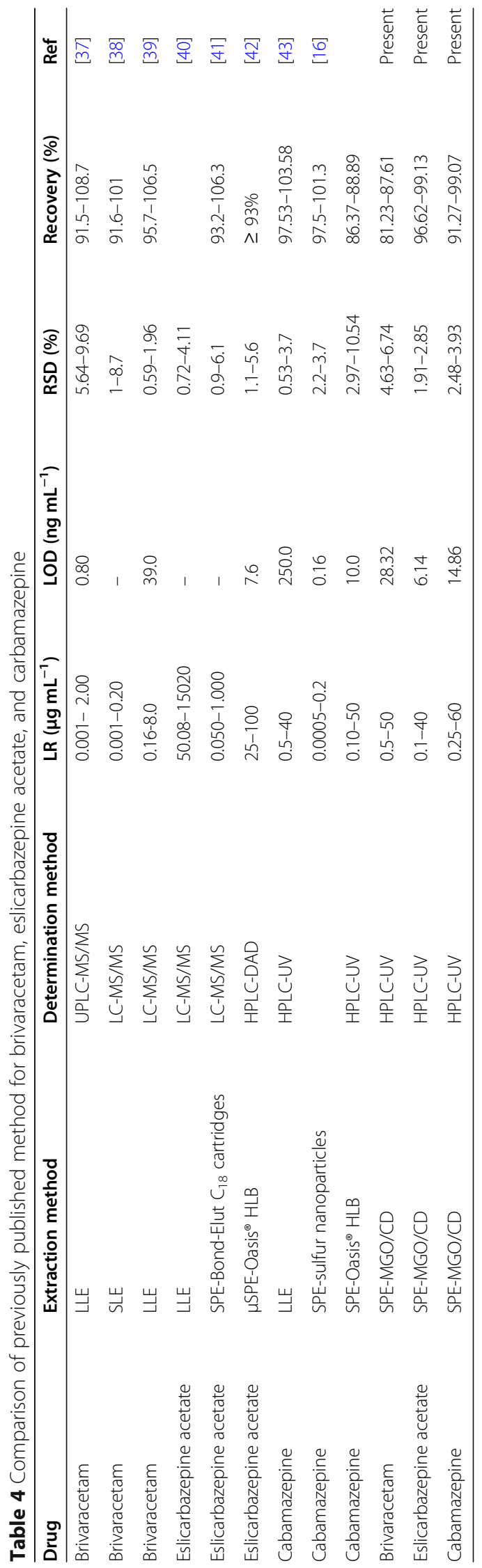


pollution. Therefore, the solid-phase extraction method is considered as an alternative method for the analysis of drugs in the plasma due to its good extraction ability, convenient operation, and consumption of a low amount of organic solvents and it needs a low amount of adsorbent. Compared with earlier reported methods by using different equipments, our method showed high precision, wider linear range, and comparable detection limit (see Table 4) [16, 3744]. These results demonstrate the advantages of the current method over the available methods, and in addition to this, there were no studies that reported on the simultaneous extraction of these three antiepileptic drugs using the solid-phase extraction method.

\section{Conclusions}

Magnetic graphene oxide composite of $\beta$-cyclodextrin with good water dispersibility was synthesized and characterized by FT-IR, SEM, and powder XRD, and the magnetic property of the material was established by VSM. The material was found to be paramagnetic with sufficient magnetization for the separation of composite with a conventional magnet. The developed material was used as MSPE sorbent for the extraction of three antiepileptic drugs from the human plasma. The method showed high precision with wider linear range and good detection limits. This developed HPLC-UV method has good efficiency for recoveries and good linearity and is simple to handle. And also, it gave low retention time for the three antiepileptic drugs within $8 \mathrm{~min}$. It provides high efficiency for the extraction of trace-level substances from the human plasma.

\section{Abbreviations}

BVC: Brivaracetam; ESL: Eslicarbazepine acetate; CBZ: Carbamazepine; GO: Graphene oxide; MGO: Magnetic graphene oxide; MGO-CD: Material graphene oxide- $\beta$-cyclodextrin; LLE: Liquid-liquid extraction; SPE: Solid-phase extraction; ACN: Acetonitrile; $\mathrm{MeOH}$ : Methanol; $\mathrm{CHCl}_{3}$ : Chloroform; TBDE: Tertiary butyl diethyl ether; EtOAc: Ethyl acetate; THF: Tetrahydrofuran; DMF: Dimethylformamide; SEM: Scanning electron microscopy; XRD: X-ray diffraction; VSM: Vibrational sample magnetometer; LOD: Limit of determination; LOQ: Limit of quantification; AED: Antiepileptic drug; SV2A: Synaptic vesicle glycoprotein 2A; RP: Reverse phase; $\mu \mathrm{g}$ : Microgram; ng: Nanogram; mL: Milliliter; v/v: Volume/volume; HPLC: High-performance liquid chromatography; M.W: Molecular weight; M.F: Molecular formulae

\section{Supplementary Information}

The online version contains supplementary material available at https://doi. org/10.1186/s43094-021-00239-x.

Additional file 1. FT-IR spectra of GO, MGO and MGO-CD.

\section{Acknowledgements}

The authors would like to thank the National Institute of TechnologyWarangal for providing essential support to carry out this research work. Thanks to Mylan and Hetero pharma laboratory managements for helping this work.

\section{Authors' contributions}

All the authors have read and approved the manuscript. BP has framed the methodology of the work and investigated and validated by performing the formal analysis. BP and JC have drafted the original paper. KV has also assisted in the formal analysis. KG and JC have visualized and supervised the overall experimental work. PN and JC have helped in the conceptualization of the work

\section{Funding}

No funding was received.

Availability of data and materials

All data and materials are available upon request.

\section{Declarations}

Ethics approval and consent to participate

This research was approved by the ethical committee of Hindu College of Pharmacy, Guntur, Andhra Pradesh, with an approval number 1263/PO/Re/S/ 09/CPCSEA, and written consent was obtained from each participant for the current study.

\section{Consent for publication}

All the participant has given their written consent for publication.

\section{Competing interests}

The authors declare that they have no competing interests.

Received: 8 October 2020 Accepted: 31 March 2021

Published online: 29 April 2021

\section{References}

1. Pitkänen A, Sutula TP (2002) Is epilepsy a progressive disorder? Prospects for new therapeutic approaches in temporal-lobe epilepsy. Lancet Neurol 1(3): 173-181. https://doi.org/10.1016/S1474-4422(02)00073-X

2. Sabu J, Regeti K, Mallappallil M, Kassotis J, Islam H, Zafar S, Khan R, Ibrahim H, Kanta R, Sen S, Yousif A, Nai Q (2016) Convulsive syncope induced by ventricular arrhythmia masquerading as epileptic seizures: case report and literature review. J Clin Med Res 8(8):610-615. https://doi.org/10.14740/ jocmr2583w

3. Marchi N, Granata T, Janigro D (2014) Inflammatory pathways of seizure disorders. Trends Neurosci 37(2):55-65. https://doi.org/10.1016/j.tins.2 013.11 .002

4. Santhosh NS, Sinha S, Satishchandra P (2014) Epilepsy: Indian perspective. Ann Indian Acad Neurol 17: 3-11

5. Wallin MT, Culpepper WJ, Nichols E, Bhutta ZA, Gebrehiwot TI, Hay SI, Khali IA, Krohn KJ, Liang X, Naghavi M, Mokdad AH (2019) Global, regional, and national burden of multiple sclerosis 1990-2016: a systematic analysis for the Global Burden of Disease Study 2016. Lancet Neurol 18(3):269-285. https://doi.org/10.1016/S1474-4422(18)30443-5

6. Trinka E, Kwan P, Lee BI, Dash A (2019) Epilepsy in Asia: disease burden, management barriers, and challenges. Epilepsia 60:7-21. https://doi.org/1 0.1111/epi.14458

7. Vaughan KA, Ramos CL, Buch VP, Mekary RA, Amundson JR, Shah M, Rattani A, Dewan MC, Park KB (2019) An estimation of global volume of surgically treatable epilepsy based on a systematic review and metaanalysis of epilepsy. J Neurosurg 130(4):1127-1141. https://doi.org/10.31 71/2018.3.JNS171722

8. Amico RD (2018) Depression in epilepsy: etiology, diagnosis and treatment. Psicol della Salut 2018:24-43

9. Matagne A, Margineanu DG, Kenda B, Michel P, Klitgaard H (2008) Anticonvulsive and anti-epileptic properties of brivaracetam (ucb 34714), a highaffinity ligand for the synaptic vesicle protein, SV2A. Br J Pharmacol 154(8): 1662-1671. https://doi.org/10.1038/bjp.2008.198

10. Rogawski MA (2008) Brivaracetam: a rational drug discovery success story. B J Pharmacol 154(8):1555-1557. https://doi.org/10.1038/bjp.2008.221

11. Tai KK, Truong DD (2007) Brivaracetam is superior to levetiracetam in a rat model of post-hypoxic myoclonus. J Neural Transm 114(12):1547-1551. https://doi.org/10.1007/s00702-007-0788-3

12. French JA, Costantini C, Brodsky A, Von Rosenstiel P (2010) Adjunctive brivaracetam for refractory partial-onset seizures: a randomized, 
controlled trial. Neurology 75(6):519-525. https://doi.org/10.1212/WNL. 0b013e3181ec7f7f

13. Malawska B, Kulig K (2008) Brivaracetam: a new drug in development for epilepsy and neuropathic pain. Expert Opin Investig Drugs 17(3):361-369. https://doi.org/10.1517/13543784.17.3.361

14. Gillard M, Fuks B, Leclerca K, Matagne A (2011) Binding characteristics of brivaracetam, a selective, high affinity SV2A ligand in rat, mouse and human brain: relationship to anti-convulsant properties. Eur J Pharmacol 664(1-3): 36-44. https://doi.org/10.1016/j.ejphar.2011.04.064

15. Klitgaard H, Matagne A, Nicolas JM, Gillard M, Lamberty Y, De Ryck M, Kaminski RM, Leclerca K, Niespodziany I, Wolff C, Wood M (2016) Brivaracetam: rationale for discovery and preclinical profile of a selective SV2A ligand for epilepsy treatment. Epilepsia 57(4):538-548. https://doi.org/1 $0.1111 /$ epi.13340

16. Ghoraba Z, Aibaghi B, Soleymanpour A (2017) Application of cationmodified sulfur nanoparticles as an efficient sorbent for separation and preconcentration of carbamazepine in biological and pharmaceutical samples prior to its determination by high-performance liquid chromatography. J Chromatogr B 1063:245-52.

17. Queiroz RH, Bertucci C, Malfará WR, Dreossi SA, Chaves AR, Valério DA, Queiroz ME (2008) Quantification of carbamazepine, carbamazepine-10,11epoxide, phenytoin and phenobarbital in plasma samples by stir barsorptive extraction and liquid chromatography. J Pharm Biomed Anal 48(2): 428-434. https://doi.org/10.1016/j.jpba.2008.03.020

18. Mohiuddin I, Berhanu AL, Malik AK, Aulakh JS, Lee J, Kim KH (2019) Preparation and evaluation of a porous molecularly imprinted polymer for selective recognition of the antiepileptic drug carbamazepine. Environ Res 176: 108580

19. Weissinger F, Losch F, Winter $Y$, Brecht $S$, Lendemans $D$, Kockelmann $E$ (2019) Effectiveness of eslicarbazepine acetate in dependency of baseline anticonvulsant therapy: results from a German prospective multicenter clinical practice study. Epilepsy Behav 101(Pt A):106574. https://doi.org/10.1 016/j.yebeh.2019.106574

20. Thomas S, Bharti A, Maddhesia PK, Shandilya S, Agarwal A, Biswas S, Bhansal V, Gupta AK, Tewari PK, Mathela CS (2012) Highly efficient, selective, sensitive and stability indicating RP-HPLC-UV method for the quantitative determination of potential impurities and characterization of four novel impurities in eslicarbazepine acetate active pharmaceutical ingredient by LC/ES. J Pharm Biomed Anal 61:165-175. https://doi.org/10.1016/j.jpba.2011.11.024

21. Boto REF, Almeida P, Queiroz JA (2008) Thiacarbocyanine as ligand in dyeaffinity chromatography. Biomed Chromatogr 288:278-288

22. Alves G, Fortuna A, Sousa J, Direito R, Almeida A, Rocha M, Falcão A, Soaresda-Silva P (2010) Enantioselective assay for therapeutic drug monitoring of eslicarbazepine acetate: no interference with carbamazepine and its metabolites. Ther Drug Monit 32(4):512-516. https://doi.org/10.1097/FTD. Ob013e3181e5c855

23. Fortuna A, Sousa J, Alves G, Falcão A, Soares-da-Silva P (2010) Development and validation of an HPLC-UV method for the simultaneous quantification of carbamazepine, oxcarbazepine, eslicarbazepine acetate and their main metabolites in human plasma. Anal Bioanal Chem 397(4):1605-1615. https:// doi.org/10.1007/s00216-010-3673-0

24. Almeida L, Soares-da-silva P (2007) Eslicarbazepine acetate ( BIA 2-093). Neurotherapeutics 4(1):88-96. https://doi.org/10.1016/j.nurt.2006.10.005

25. Bialer M, Johannessen SI, Kupferberg HJ, Levy RH, Perucca E, Tomson T (2007) Progress report on new antiepileptic drugs: a summary of the Eigth Eilat Conference (EILAT VIII). Epilepsy Res 73(1):1-52. https://doi.org/10.1016/ j.eplepsyres.2006.10.008

26. Keating GM (2014) Eslicarbazepine acetate: a review of its use as adjunctive therapy in refractory partial-onset seizures. CNS Drugs 28(7):583-600. https://doi.org/10.1007/s40263-014-0182-2

27. Szejtli J (1988) Cyclodextrin technology Kluwer Academic Publishers. Dordrecht, The Netherlands 1-66

28. Rekharsky MV, Inoue Y (1988) Complexation thermodynamics of cyclodextrins. Chem Rev 98(5):1875-1918

29. Guo Y, Guo S, Li J, Wang E, Dong S (2011) Cyclodextrin-graphene hybrid nanosheets as enhanced sensing platform for ultrasensitive determination of carbendazim. Talanta 84(1):60-64. https://doi.org/10.1 016/j.talanta.2010.12.007

30. Hapiot F, Tilloy S, Monflier E (2006) Cyclodextrins as supramolecular hosts for organometallic complexes. Chemical reviews 106(3):767-781. https://doi. org/10.1021/cr050576c
31. Connors KA (1997) The stability of cyclodextrin complexes in solution. Chemical reviews 97(5):1325-1358. https://doi.org/10.1021/cr960371r

32. Crini $G$, Morcellet M (2002) Synthesis and applications of adsorbents containing cyclodextrins. J Sep Sci 25(13):789-813. https://doi.org/10.1002/1 615-9314(20020901)25:13<789::AID-JSSC789>3.0.CO;2-J

33. Gazpio C, Sánchez M, Isasi JR, Vélaz I, Martín C, Martínez-Ohárriz C, Zornoza A (2008) Sorption of pindolol and related compounds by a $\beta$-cyclodextrin polymer: isosteric heat of sorption. Carbohydr Polymers 71(1):140-146. https://doi.org/10.1016/j.carbpol.2007.06.007

34. Zhang J, Liu D, Meng X, Shi Y, Wang R, Xiao D, He H (2017) Solid phase extraction based on porous magnetic graphene oxide/ $\beta$-cyclodextrine composite coupled with high performance liquid chromatography for determination of antiepileptic drugs in plasma samples. J Chromatogr A 1524:49-56. https://doi.org/10.1016/j.chroma.2017.09.074

35. Goud KY, Hayat A, Satyanarayana M, Kumar VS, Catanante G, Gobi KV, Marty $J L$ (2017) Aptamer-based zearalenone assay based on the use of a fluorescein label and a functional graphene oxide as a quencher. Microchim Acta 184(11):4401-4408. https://doi.org/10.1007/s00604-017-2487-6

36. Wu J, Xiao D, Zhao H, He H, Peng J, Wang C, Zhang C, He J (2015) A nanocomposite consisting of graphene oxide and $\mathrm{Fe} 3 \mathrm{O} 4$ magnetic nanoparticles for the extraction of flavonoids from tea, wine and urine samples. Microchim Acta 182(13-14):2299-2306. https://doi.org/10.1007/ s00604-015-1575-8

37. labal M, Ezzeldin E, Al-Rashood KA (2017) UPLC-MS/MS assay for identification and quantification of brivaracetam in plasma sample: application to pharmacokinetic study in rats. J Chromatogr B 1060:63-70. https://doi.org/10.1016/j.jchromb.2017.05.039

38. Bourgogne E, Culot B, Dell'Aiera S, Chanteux H, Stockis A, Nicolas JM (2018) Off-line solid phase extraction and liquid chromatography-tandem mass spectrometry method for the quantitation of brivaracetam acid metabolites: method validation and application to in vitro metabolism assays. J Chromatogr B 1086:138-145. https://doi.org/10.1016/j.jchromb.2018.04.018

39. Vasanth DA, Rajkamal B (2018) A validated LC-MS/MS method for pharmacokinetic study of brivaracetam in healthy rabbits. Int J Pharm Pharm Sci 10(2):24. https://doi.org/10.22159/ijpps.2018v10i2.21457

40. Li T, Huang B, Li D, Zhu Y, Ding L, Shu C (2019) Development and validation of a specific and sensitive LC-MS/MS method for determination of eslicarbazepine in human plasma and its clinical pharmacokinetic study. J Chromatogr B 1112:61-66. https://doi.org/10.1016/j.jchromb.2019.02.027

41. Loureiro Al, Fernandes-Lopes C, Wright LC, Soares-da-Silva P (2011) Development and validation of an enantioselective liquid-chromatography/ tandem mass spectrometry method for the separation and quantification of eslicarbazepine acetate, eslicarbazepine, R-licarbazepine and oxcarbazepine in human plasma. J Chromatogr B Anal Technol Biomed Life Sci 879(25): 2611-2618. https://doi.org/10.1016/j.jchromb.2011.07.019

42. Servais AC, Janicot B, Takam A, Crommen J, Fillet M (2016) Liquid chromatography separation of the chiral prodrug eslicarbazepine acetate and its main metabolites in polar organic mode. Application to their analysis after in vitro metabolism. J Chromatogr A 1467:306-311. https://doi. org/10.1016/j.chroma.2016.07.022

43. Mowafy HA, Alanazi FK, El Maghraby GM (2012) Development and validation of an HPLC-UV method for the quantification of carbamazepine in rabbit plasma. Saudi Pharm J 20(1):29-34. https://doi.org/10.1016/j.jsps.2 011.04 .003

44. Serralheiro A, Alves G, Fortuna A, Rocha M, Falcão A (2013) First HPLC-UV method for rapid and simultaneous quantification of phenobarbital, primidone, phenytoin, carbamazepine, carbamazepine-10,11-epoxide, 10,11trans-dihydroxy-10,11-dihydrocarbamazepine, lamotrigine, oxcarbazepine and licarbazepine in human plasma. J Chromatogr B Anal Technol Biomed Life Sci 925:1-9. https://doi.org/10.1016/j.jchromb.2013.02.026

\section{Publisher's Note}

Springer Nature remains neutral with regard to jurisdictional claims in published maps and institutional affiliations. 